\title{
A Rare Recurrent 4q25 Proximal Deletion Not Involving the PITX2 Gene: A Genomic Disorder Distinct from Axenfeld-Rieger Syndrome
}

\author{
Jennifer L. Heithaus ${ }^{a}$ Kimberly A. Twyman ${ }^{a} \quad$ Jacqueline R. Batanian ${ }^{b, c}$ \\ Departments of Pediatrics, a Developmental Pediatrics Division, and ${ }^{b}$ Genetics Division, Saint Louis University \\ School of Medicine, and 'Molecular Cytogenetics Laboratory, SSM Cardinal Glennon Children's Hospital, \\ St. Louis, Mo., USA
}

\section{Key Words \\ COL25A1 - Developmental delay · EGF · Hypotelorism .}

Hypotonia · Mandible asymmetry · Microdeletion 4q25

\begin{abstract}
Haploinsufficient microdeletions within chromosome $4 q 25$ are often associated with Axenfeld-Rieger syndrome. A de novo $4 \mathrm{q} 25$ deletion, $675 \mathrm{~kb}$ proximal to PITX2, has previously been reported once in an adult patient. The patient did not have Axenfeld-Rieger anomaly, but instead had intellectual disability and a complex behavioral phenotype with withdrawn, stereotypic, and ritualistic behavior. Array comparative genome hybridization demonstrated a smaller, overlapping 4 q25 deletion in a 2-year-old patient and his mother, both having significant phenotypic overlap with the initially reported patient. All 3 patients have distinct facial features (including mild hypotelorism and subtle mandibular asymmetry), developmental delay, and complex behavioral difficulties. A genotype-phenotype correlation narrows the shared phenotype to a common COL25A1 gene aberration and proposes that the concurrent EGF gene loss has a significant impact on the phenotypic severity. Overall, our patients provide data to support the existence of a novel $4 q 25$ proximal deletion syndrome.

(c) 2016 S. Karger AG, Basel
\end{abstract}

A de novo $1.2 \mathrm{Mb}-4 \mathrm{q} 25$ proximal microdeletion encompassing the genes COL25A1 and ELOVL6 has been reported once in a 20 -year-old woman. She had dysmorphic features and a complex behavioral phenotype, as described in table 1 [Verhoeven et al., 2013]. Through genotype-phenotype correlation, COL25A1 and EGF were proposed as candidate genes responsible for her unique phenotype [Verhoeven et al., 2013]. Prior to that publication, 4q25 microdeletion syndrome was mostly associated with Axenfeld-Rieger syndrome, with $95 \%$ of the affected patients having mutations or deletions involving the PITX2 gene or related upstream regulatory genes, often in a haploinsufficient manner [Amendt et al., 2000; Becker et al., 2003]. Here, we report on 2 additional patients (a child and his mother) having a smaller, but overlapping deletion characterized by a common behavioral and physical phenotype. The 3 patients combined suggest the existence of a novel $4 \mathrm{q} 25$ proximal deletion syndrome.

\section{Patients and Methods}

Clinical Case Findings

A 29-month-old Caucasian boy presented to our clinic with his 19-year-old mother. His medical history included birth via Cesarean section for fetal distress, eczema, and seasonal allergies.

\section{KARGER}

E-Mail karger@karger.com

www.karger.com/msy
(C) 2016 S. Karger AG, Basel

$1661-8769 / 16 / 0073-0138 \$ 39.50 / 0$
Jacqueline R. Batanian, $\mathrm{PhD}$

Saint Louis University School of Medicine, SSM Cardinal Glennon Children's Hospital 1465 S. Grand Blvd

St. Louis, MO 63104 (USA)

E-Mail batanijr@slu.edu 
Fig. 1. a Frontal view of the patient demonstrating minor dysmorphic features, including subtle facial asymmetry (most prominent in his mandible), mild hypotelorism, borderline low-set ears, long nasal bridge, and narrow lips. b The patient and his mother showing similarity in their facial characteristics.
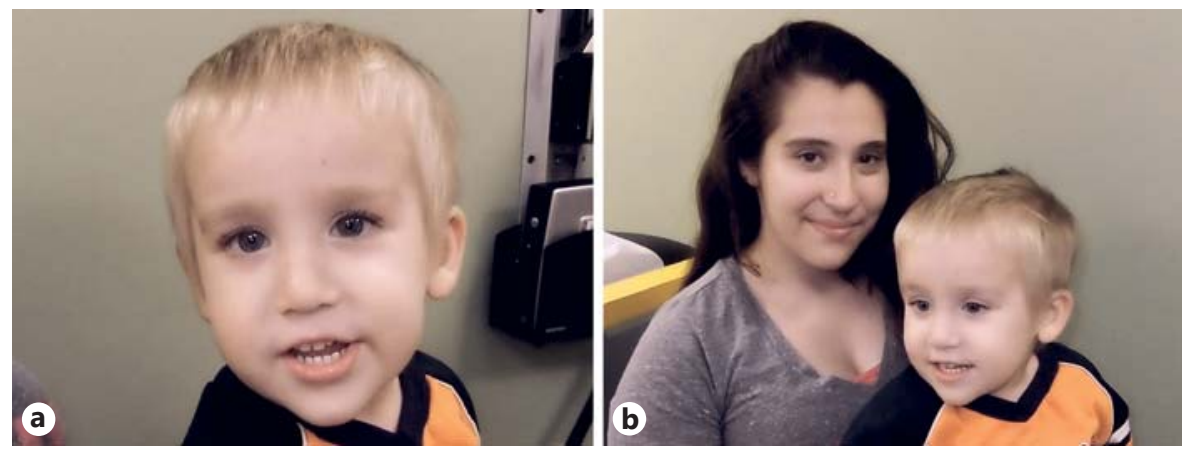

Table 1. Genomic coordinates and clinical features of cases with proximal 4q25 microdeletion

\begin{tabular}{|c|c|c|c|}
\hline & Verhoeven et al., 2013 & Proband & Parent \\
\hline $\begin{array}{l}\text { Deletion positions in } \\
\text { chromosome } 4 \mathrm{q} 25\end{array}$ & $110,101,176-111,337,864$ (hg19) & $109,762,498-110,803,661$ (hg19) & $109,762,498-110,803,661$ (hg19) \\
\hline Sex & female & male & female \\
\hline Age & 20 years & 29 months & 19 years \\
\hline Developmental delay & $\begin{array}{l}\text { confirmed gross motor, probable } \\
\text { language }\end{array}$ & $\begin{array}{l}\text { social, speech, and fine motor } \\
\text { (development quotients } \sim 70 \text { ) }\end{array}$ & speech \\
\hline Intellectual disability & $+($ mild $)$ & ? & - \\
\hline Learning disability & $+($ unspecified type $)$ & $?$ & $+($ unspecified type $)$ \\
\hline Cognitive deterioration & + & $?$ & - \\
\hline Behavior problems & $\begin{array}{l}\text { ritualistic, withdrawn, dysthymia, flat } \\
\text { affect, tics, perseverations, stereotyped } \\
\text { behaviors, auditory psychosis, social } \\
\text { immaturity and difficulty }\end{array}$ & $\begin{array}{l}\text { preference for play alone, pica, } \\
\text { emotional dysregulation, tactile and } \\
\text { auditory processing difficulties, } \\
\text { preference for organization in } \\
\text { surroundings }\end{array}$ & $\begin{array}{l}\text { preference for self, anxiety, bipolar- } \\
\text { depression, preference for organization } \\
\text { in surroundings, difficulty with } \\
\text { disruptions, social difficulty due to } \\
\text { nervousness }\end{array}$ \\
\hline Growth retardation & - & + & $?$ \\
\hline Short stature & - & + & + \\
\hline Hypotonia & + & + & + \\
\hline Joint laxity & + & + & - \\
\hline Facial dysmorphisms & $\begin{array}{l}\text { hypotelorism, narrow mouth, } \\
\text { mandible asymmetry, deeply set eyes, } \\
\text { small ears, short palpebral fissures }\end{array}$ & $\begin{array}{l}\text { hypotelorism (3rd-25th centile), narrow } \\
\text { mouth, mandible asymmetry, long nasal } \\
\text { bridge, borderline low-set ears }\end{array}$ & $\begin{array}{l}\text { hypotelorism ( } 3 \text { rd- } 25 \text { th centile), narrow } \\
\text { mouth, mandible asymmetry, long nasal } \\
\text { bridge }\end{array}$ \\
\hline Other dysmorphisms & $\begin{array}{l}\text { long fingers, bilateral short } 5 \text { th } \\
\text { metacarpals, broad neck, low posterior } \\
\text { hairline }\end{array}$ & $\begin{array}{l}\text { short hands ( } \leq 3 \text { rd centile) and palms } \\
\text { (3rd-25th centile), bilateral short } 5 \text { th } \\
\text { metacarpals, } 2 \text { posterior parietal hair } \\
\text { whorls }\end{array}$ & $\begin{array}{l}\text { short hands and palms (all 3rd-25th } \\
\text { centile), bilateral short 5th metacarpals }\end{array}$ \\
\hline Eye abnormalities & - & none grossly & decreased visual acuity \\
\hline Other & $\begin{array}{l}\text { normal head CT, cardiac ECHO, and } \\
\text { EEG, normal laboratory evaluation } \\
\text { (not specified), brain MRI with } 2 \text { small } \\
\text { high-signal white matter lesions in L } \\
\text { frontal lobe }\end{array}$ & $\begin{array}{l}\text { normal bone age, and normal CMP, } \\
\text { lead, TTG IgA, IGF- } \beta \text {, TSH, and FT4 } \\
\text { levels, CBC with mild anemia, low } \\
\text { ferritin level }\end{array}$ & - \\
\hline
\end{tabular}

$\mathrm{CBC}=$ Complete blood count $\mathrm{CMP}=$ comprehensive metabolic panel; FT4 = free thyroxine 4 ; IGF- $\beta=$ insulin growth-like factor- $\beta$; TTG IgA = tissue transglutaminase-IgA; TSH = thyroid-stimulating hormone; + = present; - = not present; ? = undetermined at this point in time.

Starting at 12 months of age, he had a steady decline in growth from the 50th percentile in weight and length to current percentiles. Concerns for developmental delay and behavior difficulties started at 18 months. Developmental-behavioral assessment revealed delays in multiple realms of development as well as a complex pattern of behavioral difficulties, as described in table 1 . He did not meet criteria for a diagnosis of autism spectrum disorder. On physical assessment, he was normocephalic (50th percentile), but height and weight were below the 3rd percentile. Other physical examination findings and medical studies (including laboratory evaluation for poor growth) are presented in figure 1 and table 1. 


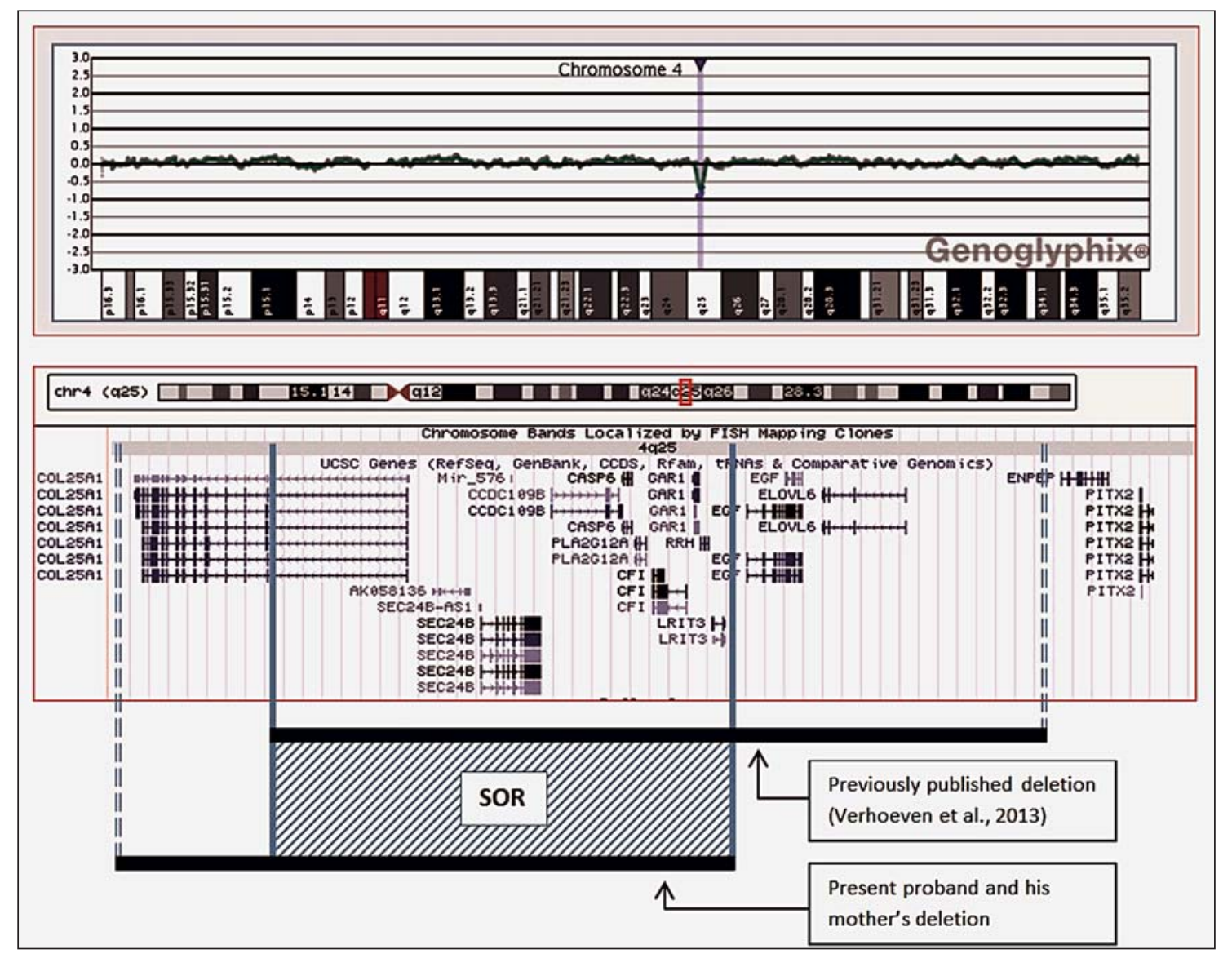

Fig. 2. The interstitial deletion of $4 \mathrm{q} 25$ with the following genomic coordinates: $\operatorname{arr}[\mathrm{hg} 19] 4 \mathrm{q} 25(109,762,498-$ $110,803,661) \times 1$. The deletion encompasses the following OMIM genes: COL25A1, SEC24B, CASP6, PLA2G12A, CFI, GAR1, RRH, and LRIT3. The centromeric junction breakpoint falls within the 32nd intron of COL25A1 leading to a partial deletion, and the telomeric junction breakpoint is beyond the LRIT3 gene and does not fall within a gene. The previously published and the present deleted regions are compared by parallel lines; the smallest overlapping region of the 2 deletions is denoted as SOR.

His mother's medical history included term birth, asthma, decreased visual acuity requiring glasses, and tonsillectomy with adenoidectomy. She had a history of speech delay and an unspecified learning disability. Her physical examination included normal weight and head circumference (both 50-90th percentile), but short stature ( $<5$ th percentile). Other physical and behavioral phenotypic features are noted in figure 1 and table 1 . The father's medical history was not available.

\section{Methods and Results}

An array comparative genome hybridization (aCGH) using Agilent 4-Sureplex array (Agilent, Santa Clara, Calif., USA) performed on our patient revealed an isolated copy number variation, consisting of an interstitial deletion: arr[hg19] 4q25(109,762,498$110,803,661) \times 1$. This abnormality is characterized by a copy loss of 25 oligonucleotide probes in the region of 4q25 (fig. 2). It is a minimum size of $1.04 \mathrm{Mb}$ and a maximum size of $1.14 \mathrm{Mb}$ due to gaps in the regions represented on the microarray. Fluorescence in situ hybridization (FISH) of RP11-2091M15 (Empire Genomic, N.Y., USA) (204 kb, 100\% within region of interest) and specific fluorescent-labeled centromere chromosome 4 probes (CEP4) (Abbott Molecular, Des Plains, IlI., USA) performed on the proband and his mother showed 1 signal of RP11 and 2 signals of CEP4 (fig. 3), confirming the deletion in the proband and identifying its origin as maternally inherited: ish del(4)(q25q25)(D4Z1+, RP11-1091M15-)mat. A full maternal aCGH was not completed, given the confirmation of inheritance via FISH.

The deletion encompasses the following protein-coding (OMIM) genes: COL25A1, SEC24B, CASP6, PLA2G12A, CFI, GAR1, RRH, and LRIT3. The proximal breakpoint junction falls within COL25A1 (reversed gene) in the intron (32/37); therefore, it is partially deleted, whereas exons $31-1$ are completely deleted. The distal breakpoint does not fall within a gene. The deletion is $675 \mathrm{~kb}$ proximal to PITX2, the gene associated with AxenfeldRieger syndrome [Amendt et al., 2000]. 


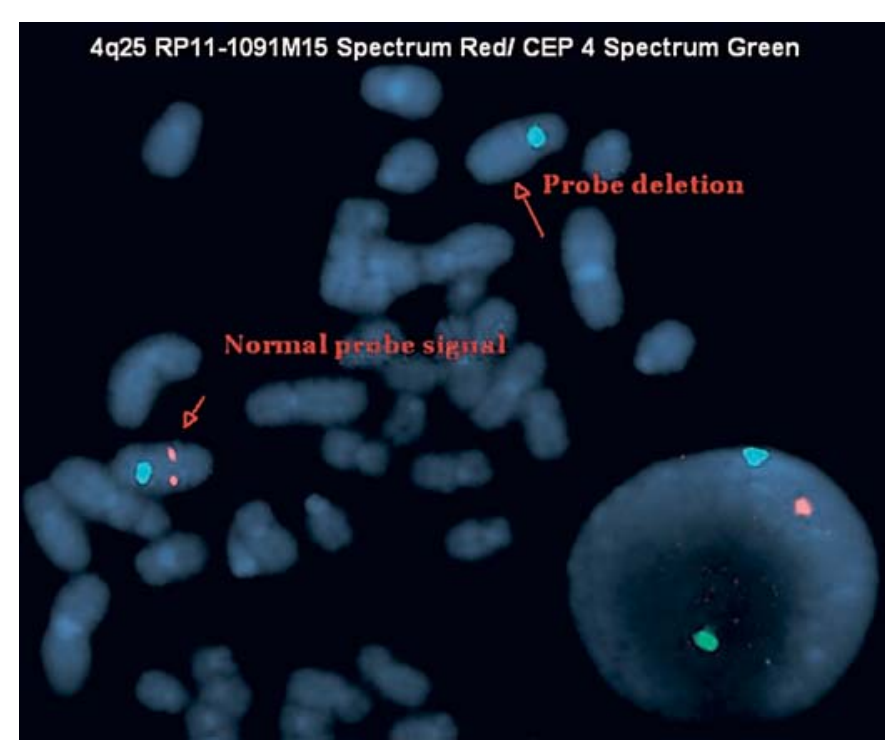

Fig. 3. FISH analysis of the clone RP11-1091M15 (Spectrum Red) and the specific chromosome centromere 4 (D4Z1) (Spectrum Green) on metaphase and interphase cells showing 1 signal of the deleted clone, confirming the deletion identified by aCGH.

\section{Discussion}

Our patient has a 1.2-Mb 4q25 proximal deletion near the PITX2 gene, yet he is without phenotypic features of Axenfeld-Rieger syndrome. Given this is an isolated copy number variation in our patient, it is the most probable candidate for the complex phenotype observed. This is further supported by the fact that his mother has an identical deletion and a shared phenotype. No identical deletions are described and/or phenotypically related in the Database of Genomic Variants or Decipher [MacDonald et al., 2014]. As previously mentioned, a similar overlapping $1.2-\mathrm{Mb}$ deletion was described earlier in a 20 -yearold female. Similarly, she did not have clinical features of Axenfeld-Rieger syndrome [Verhoeven et al., 2013]. All 3 patients share the loss of COL25A1, SEC24B, CASP6, PLA2G12A, CFI, GAR1, RRH, and LRIT3 [Verhoeven et al., 2013]. The remaining genes in the first-described patient, EGF and ELOVL6, were excluded from our reported deletion [Verhoeven et al., 2013]. Additionally, the proximal breakpoint junction in COL25A1 is different between families; our reported deletion falls within intron 32, whereas the prior reported was within intron 36 [Verhoeven et al., 2013].

As described in table 1, the 3 patients have a common physical and behavioral phenotype. The 20 -year-old pa- tient additionally has phenotypic features that are more severe and/or are not found in our family: mild intellectual disability with possible cognitive deterioration, and a more severe psychiatric illness with ritualistic behaviors and auditory hallucinations [Verhoeven et al., 2013]. She also had unique dysmorphisms not shared with our proband's mother, with deeply set eyes, a broad neck, and a low posterior hair line [Verhoeven et al., 2013]. On the other hand, she did not possess the short stature and short hands and palms found in our 2 patients.

COL25A1 and EGF were the 2 proposed candidate genes for the phenotype seen in the original patient [Verhoeven et al., 2013]. Logically, as the 3 patients' deletions are overlapped by a partial loss of COL25A1, the abnormality of this gene may potentially be responsible for the $4 \mathrm{q} 25$ proximal deletion syndrome. The impact of the EGF deletion may contribute to the phenotype severity or may allow for complete penetrance.

COL25A1, otherwise known as collagen XXV a1 (OMIM 61004), produces a membrane-bound collagen in neurons and has been implicated to play a role in mental health pathologies, including Alzheimer disease [Hashimoto et al., 2002]. Through 2 separate genome-wide association analyses, COL25A1 has been proposed as a candidate to influence the age of onset of schizophrenia and has been associated with the development of antisocial personality disorder in adults with substance abuse [Wang et al., 2011; Li et al., 2012]. The variability in mental health pathologies reported is consistent with the complex behavioral phenotype encountered in the 3 presently discussed patients. The shared hypotonia found in the 3 patients may also be due to the partial deletion of the COL25A 1 gene, as COL $25 \mathrm{~A} 1$ is required for proper intramuscular motor intervention during early development, demonstrated by knockout mouse studies [Tanaka et al., 2014; Shinwari et al., 2015].

EGF (OMIM 131530) encodes for a cleaved-product peptide hormone and plays a role in cell differentiation as well as ectodermal and mesodermal cell division [Urdea et al., 1983; Groenestege et al., 2007]. It has variable expression in human tissues, with high expression in the cerebrum and absent expression in the cerebellum [Groenestege et al., 2007]. Additionally, it has been suspected to be involved in the pathogenesis of schizophrenia in human patients and in animal models [Futamura et al., 2002]. In an unrelated study, a heterozygous carrier of an EGF mutation (C3209T) had a diagnosis of schizophrenia, whereas a patient with homozygous mutation (C3209T) developed primary hypomagnesemia [Groenestege et al., 2007]. Combining this information, one copy 
deletion of the gene may be implicated in mental illness, namely schizophrenia.

As proposed above, the loss of COL25A1 compounded with the loss of $E G F$ may be contributing to the more severe phenotype of the 20-year-old woman. The studies of Groenestege et al. [2007], Wang et al. [2011], and Futamura et al. [2002] reveal there is support that combined loss of EGF and COL25A1 may act as a '2-hit' scenario, increasing the likelihood of schizophrenia. This combined effect may explain the 20-year-old patient's 'obsessive ritualistic behaviors... [and] vague ideas of reference and 'auditory hallucinations', ' traits absent in our reported family [Verhoeven et al., 2013].

The loss of the other genes shared by the 3 patients are less likely causative of their common presentation, especially since none have been associated with clinically related pathological changes or changes in heterozygous form. SEC24B (OMIM 607184) produces a protein that transports secretory proteins within cells and has been speculated to play a role in neural tube formation in humans [Yang et al., 2013]. In a knockout mouse model, Casp6 ${ }^{-/-}$(OMIM 601532) mice were hypoactive and displayed learning deficits, and on autopsy had increased cortical volume and abnormal axonal growth through the corpus callosum [Uribe et al., 2012]. However, mice with a heterozygous deletion of the gene behaved similar to the wild type [Uribe et al., 2012]. CASP6 is otherwise involved in programmed axonal degeneration and is proposed to be involved the pathogenesis of Alzheimer disease and Huntington disease, clinically unrelated to our patients [Nikolaev et al., 2009; Uribe et al., 2012].

PLA2G12A (OMIM 611652), a unique phospholipase expressed in multiple human tissues, has weak lipid hydrolase activity that may promote neurogenesis but thus far has only been associated with olfactory sensory structure genesis [Muñoz-Sanjuán and Brivanlou, 2005]. Haploinsufficiency of CFI (OMIM 217030), a serine proteinase modulator of the complement pathway, is a risk for the development of atypical hemolytic uremic syndrome [Caprioli et al., 2006]. It otherwise has been correlated with age-related macular degeneration [Seddon et al., 2013]. There is limited and unrelated information known on GAR1 (also NOLA1; OMIM 606468): it has been proposed as a nonvital component of H/ACA small nucleolar RNPs and telomerase in vivo [Dragon et al., 2000]. $R R H$ (OMIM 605224) encodes for a G-protein-coupled receptor that has been localized solely to the retinal pigment epithelium [Sun et al., 1997]. Finally, LRIT-3 (OMIM 615004) is expressed in the brain and the eye, and has been implicated in complete congenital stationary night blindness in 2 different pedigrees with compound heterozygous mutations, but has not demonstrated effects on mental health [Kim et al., 2012; Zeitz et al., 2013].

Most common recurrent genomic disorders are caused by nonallelic homologous recombination of low copy repeats or are caused by segmental duplications located at breakpoint junctions [Emanuel and Shaikh, 2001; Béna et al., 2010]. Due to the richness of these repeats, nested or distant deletions within a recurrent common large deletion have been associated with distinct syndromes, as found in deletions of 22q11.2 and 15q11.2 [Emanuel and Shaikh, 2001]. However, in the case of rare recurrent deletion/duplication, the mutated region may lack segmental duplications. Per the genome browser of the University of California Santa Cruz (UCSC; www.genome.ucsc. edu), the present deleted region has no segmental duplications. Instead, in our deletion, the junction breakpoints have simple tandem repeats. A similar type of repeat was identified in a rare recurrent $1.1-\mathrm{Mb} 14 \mathrm{q} 32.2$ genomic deletion with large tandem repeats of [Béna et al., 2010]. This supports the notion that the mechanism behind rare recurrent genomic deletion/duplication is caused by simple tandem repeats and not by low copy number, and suggests a possible mechanism in this reported case.

Collectively, the 3 reported patients form a group of individuals with a novel inheritable $4 \mathrm{q} 25$ proximal deletion syndrome, sharing overlapping phenotypes likely attributed to the deletion of COL25A1. Furthermore, deletion of a contiguous region that completely includes the $E G F$ gene gives a related, more severe phenotype as seen in the 20 -year-old patient. Overall, the 3 patients together are strongly suggestive of a haploinsufficient region and a 4q25 proximal deletion syndrome, characterized by distinct dysmorphic physical features, mild hypotonia, developmental delay, and social and behavioral difficulties.

\section{Statement of Ethics}

Involved patients (or parents) provided written informed consent regarding their involvement in the manuscript.

\section{Disclosure Statement}

The authors declare no conflicts of interest. 


\section{References}

-Amendt BA, Semina EV, Alward WLM: Rieger syndrome: a clinical, molecular, and biochemical analysis. Cell Mol Life Sci 57:16521666 (2000).

Becker SA, Popp S, Rager K, Jauch A: A new case of an interstitial deletion (4)(q25q27) characterised by molecular cytogenetic techniques and review of the literature. Eur J Pediatr 162: 267-270 (2003).

- Béna F, Gimelli S, Migliavacca E, Brun-Druc N, Buiting K, et al: A recurrent 14q32.2 microdeletion mediated by expanded TGG repeats. Hum Mol Genet 19:1967-1973 (2010).

-Caprioli J, Noris M, Brioschi S, Pianetti G, Castelletti F, et al: Genetics of HUS: the impact of $M C P, C F H$ and IF mutations on clinical presentation, response to treatment, and outcome. Blood 108:1267-1279 (2006).

Dragon F, Pogačić V, Filipowicz W: In vitro assembly of human H/ACA small nucleolar RNPs reveals unique features of U17 and telomerase RNAs. Mol Cell Biol 20:30373048 (2000).

Emanuel BS, Shaikh TH: Segmental duplications: an 'expanding' role in genomic instability and disease. Nat Rev Genet 2:791-800 (2001).

Futamura T, Toyooka K, Iritani S, Niizato K, Nakamura R, et al: Abnormal expression of epidermal growth factor and its receptor in the forebrain and serum of schizophrenic patients. Mol Psychiatry 7:673-682 (2002).

-Groenestege WM, Thébault S, van der Wijst J, van den Berg D, Janssen R, et al: Impaired basolateral sorting of pro-EGF causes isolated recessive renal hypomagnesemia. J Clin Invest 117:2260-2267 (2007).

-Hashimoto T, Wakabayashi A, Watanabe A, Kowa H, Hosoda R, et al: CLAC: a novel Alzheimer amyloid plaque component derived from a transmembrane precursor, CLAC-P/ collagen type XXV. EMBO J 21:1524-1534 (2002).

Kim SD, Liu JL, Roscioli T, Buckley MF, Yagnik $\mathrm{G}$, et al: Leucine-rich repeat, immunoglobulin-like and transmembrane domain 3 (LRIT3) is a modulator of FGFR1. FEBS Lett 586:1516-1521 (2012)

Li D, Zhao H, Kranzler HR, Oslin D, Anton RF, et al: Association of COL25A1 with comorbid antisocial personality disorder and substance dependence. Biol Psychiatry 71:733-740 (2012).

-MacDonald JR, Ziman R, Yuen RK, Feuk L, Scherer SW: The database of genomic variants: a curated collection of structural variation in the human genome. Nucleic Acids Res 42(database issue):D986-D992 (2014).

-Muñoz-Sanjuán I, Brivanlou AH: Induction of ectopic olfactory structures and bone morphogenetic protein inhibition by Rossy, a group XII secreted phospholipase $\mathrm{A}_{2}$. Mol Cell Biol 25:3608-3619 (2005).

- Nikolaev A, McLaughlin T, O'Leary DD, TessierLavigne M: APP binds DR6 to trigger axon pruning and neuron death via distinct caspases. Nature 457:981-989 (2009).

Seddon JM, Yu Y, Miller EC, Reynolds R, Tan PL, et al: Rare variants in $C F 1, C 3$ and $C 9$ are associated with high risk of advanced age-relat ed macular degeneration. Nat Genet 45:13661370 (2013).

Shinwari JM, Khan A, Awad S, Shinwari Z, Alaiya A, Alanazi M, Tahir A, Poizat C, Al Tassan N: Recessive mutations in COL25A1 are a cause of congenital cranial dysinnervation disorder. Am J Hum Genet 96:147-152 (2015).

Sun H, Gilbert DJ, Copeland NG, Jenkins NA, Nathans J: Peropsin, a novel visual pigmentlike protein located in the apical microvilli of the retinal pigment epithelium. Proc Natl Acad Sci USA 94:9893-9898 (1997).

- Tanaka T, Wakabayashi T, Oizumi H, Nishio S, Sato T, et al: CLAC-P/collagen type XXV is required for the intramuscular innervation of motorneurons during neuromuscular development. J Neurosci 34:1370-1379 (2014).

-Urdea MS, Merryweather JP, Mullenbach GT, Coit D, Heberlein U, et al: Chemical synthesis of a gene for human epidermal growth factor urogastrone and its expression in yeast. Proc Natl Acad Sci USA 80:7461-7465 (1983).

Uribe V, Wong BK, Graham RK, Cusack CL, Skotte NH, et al: Rescue from excitotoxicity and axonal degeneration accompanied by age-dependent behavioral and neuroanatomical alterations in caspase-6-deficient mice. Hum Mol Genet 21:1954-1967 (2012).

-Verhoeven WM, Egger JI, Goffin L, van Zutven LJ, Mancini GM: Behavioural phenotype of a patient with a de novo $1.2 \mathrm{Mb}$ chromosome 4q25 microdeletion. Eur J Med Genet 56:331335 (2013).

Wang KS, Liu X, Zhang Q, Aragam N, Pan Y: Genome-wide association analysis of age at onset in schizophrenia in a European-American sample. Am J Med Genet B Neuropsychiatr Genet 156B:671-680 (2011)

Yang XY, Zhou XY, Wang QQ, Li H, Chen Y, et al: Mutations in the COPII vesicle component gene SEC24B are associated with human neural tube defects. Hum Mutat 34:1094-1101 (2013).

Zeitz C, Jacobson SG, Hamel CP, Bujakowska K, Neuillé $M$, et al: Whole-exome sequencing identifies LRIT3 mutations as a cause of autosomal-recessive complete congenital stationary night blindness. Am J Hum Genet 92:6775 (2013). 